\title{
Manual of basic physiotherapeutic exercises for family and caregivers of stroke patients
}

\author{
Dérrick Patrick Artioli ${ }^{1}$ and Gladson Ricardo Flor Bertolini ${ }^{2 *}$ \\ ${ }^{1}$ Professor of the Centro Universitário Lusíada, UNILUS, Santos, SP - Brazil; Physiotherapist at the Centro Municipal de Reabilitação de Itanhaém, SP - Brazil \\ ${ }^{2}$ Professor at the Universidade do Oeste do Paraná, UNIOESTE, Cascável, PR - Brazil
}

Stroke sequelae need to be addressed early and many can even be prevented. This is when physiotherapy starts a few days after the hospital release (or the admission may even be in the place of hospitalization itself), when there is an effort by the patient to resume functions and when the family or caregiver is engaged in stimulating the same. This facilitates the recovery of simple functions, such as posture changes from dorsal decubitus to sedestation, evolving to independent gait and more elaborate activities such as driving. In addition to increasing the chances of motor improvement, early and disciplined stimulation minimizes shortening and deformities such as those reflected by a spastic pattern (shortening for example of flexors muscles of fingers and wrist, biceps brachii and sural triceps generating deformities in flexion of wrist and fingers, elbow and plantar flexion) or poor limb positioning during the flaccid phase $[1,2]$.

When considering the patient's primary need for self-help, it is worth noting that brain injuries can lead to cognitive, emotional and behavioral changes, complicating the efforts that should be made in an active way by the patient, either in physiotherapy or at home. The patient - family - caregiver relationship is also part of this long - lasting rehabilitation process, which needs to be harmonious and effective, either to guide the patient to physiotherapy (or other professionals) and especially to follow and follow the guidelines provided by the professional. Even if all factors are promising, considering the brain injury itself, depending on the area and extent of aggravation, it may be a complex limiting the expected general recovery $[3,4]$.

Some obstacles can compromise this fundamental involvement mentioned above, reducing the chances of a good prognosis. For example, those who intend to undergo neurological physiotherapy in Brazil through the Public Unique Health System - Sistema Único de Saúde, SUS - do not always start the service quickly (waiting list or reduced professional contingent) or are not attended more than once or twice a week, in sessions with minimum stimulation time. Climatic conditions can also interfere with the weekly access process to the physiotherapist, as in North American, European and Asian countries, during the rigorous winters, making it difficult for frequent doctor visits. And so, an illustrated guide using a simple description, based on the newest science evidence based indications, showing clear directions of exercise execution and the suppose level of difficulty, might be a useful tool between physiotherapist and patient, to compensate or optimize the lack of weekly sessions, objectifying higher gains and facilitating stroke recovery [5].

For guidance and practical assistance of some tasks that can be performed at home with the help of family members or caregiver, an illustrative manual is proposed, a basic guide to be followed for adequate primary stimulation (Annex 1). This proposal does not replace physiotherapy sessions, nor does it address the motor frame of each patient, therefore, it serves only as a guide and reminder of how to perform some of the many possibilities of stimulation. In any case, it is a sine qua non condition that exercises prescribed by the physiotherapist are performed, in order to achieve the best possible functional recovery within the specificity of the lesion.

Lomaglio and Perry [6] formulated a guide for the prescription of exercises after stroke based on scientific evidence. In this, they described frequency of 3-5 times per week for aerobic exercises, lasting 20-60 minutes, which could be walking, exercise bicycle, cycloergometer (for upper or lower limbs) or even sports activities, depending on the patient's motor capacity. As for the resisted, the practice should be 2 - 3 times a week, with $1-3$ sets of $10-15$ repetitions in $8-10$ exercises. Billinger, et al. [7] also advocate the prescription of aerobic activity, muscle strengthening, exercise use to reduce sedentary behavior, and secondary prevention of risk of another stroke episode. However, the manual here reproduces daily situations (such as change of position, transfer of load and gait) that do not fit directly into this didactic division suggested by the authors. Therefore, the physiotherapist should be based on the capacity and quality of the task performed by the patient, and then determine if the patient will do such activity by time, repetitions or any other form of measurement. The information in this manual is based on "The 2018 Guidelines for The Early Management of Patients with Stroke from The American Heart Association/American Stroke [5], from the HOPE - A Stroke Recovery Guide from the National Stroke Association" [8] in accordance with the The American Academy of Neurology [9], correlating with the possibility of execution by most patients. However, again emphasizing the non-approach of specific characteristics after stroke, for evading the scope of this communiqué.

The manual to subscribe makes use of colloquial language to facilitate the understanding of those to follow and to apply the information provided. It has images for the understanding of the positions to be adopted and arrows demonstrate the direction or action of the movement. Each exercise has a letter (E, I or D) that reinforces the probable difficulty level (Easy, Intermediate or Difficult) of the same, however, it is only a generalist form of classification, since it

${ }^{\star}$ Correspondence to: Gladson RF Bertolini, Professor, State University of Western Paraná, Unioeste, Cascavel, Paraná, Brazil, Tel: 45 3220-3157; E-mail: gladson_ricardo@yahoo.com.br

Received: May 26, 2018; Accepted: June 05, 2018; Published: June 09, 2018 
does not consider the individuality of the patient. The progression of the exercises should occur through the analysis of the responsible physiotherapist, ascertaining the performance without compensations, done with adequate execution speed and when getting tired minimally with the repetitions [1]. No elaborate or advanced technique is used because the proposal is reproducibility at home (Figures 1-7).

Figure 1. Weight Bearing, Flexibility, and Movement Control Exercises for the Affected Upper Limb.

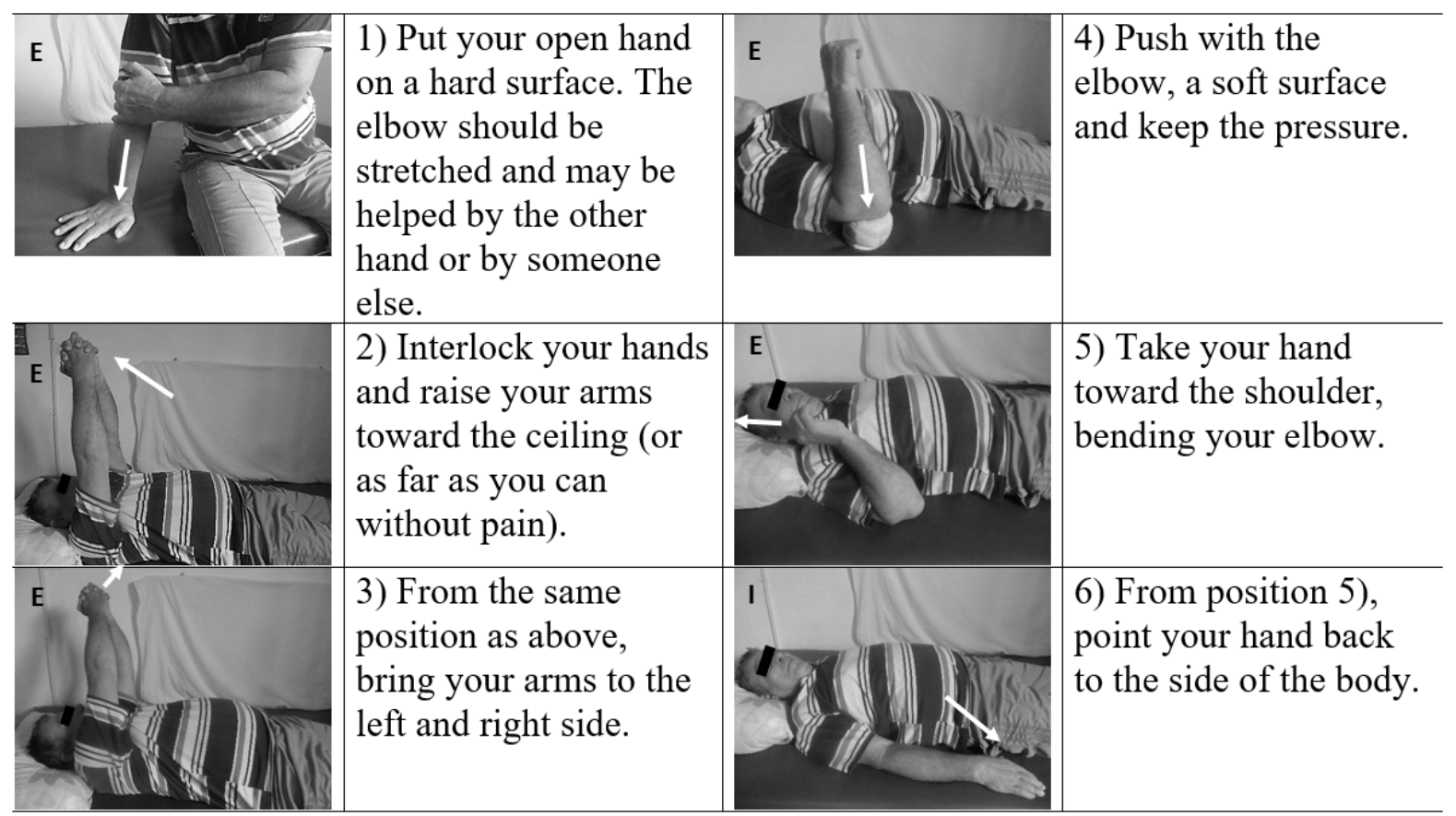

Difficulty: E - Easy; I - Intermediate; D - Difficult

Figure 2. Flexibility and Movement Control Exercises for the Affected Upper Limb.

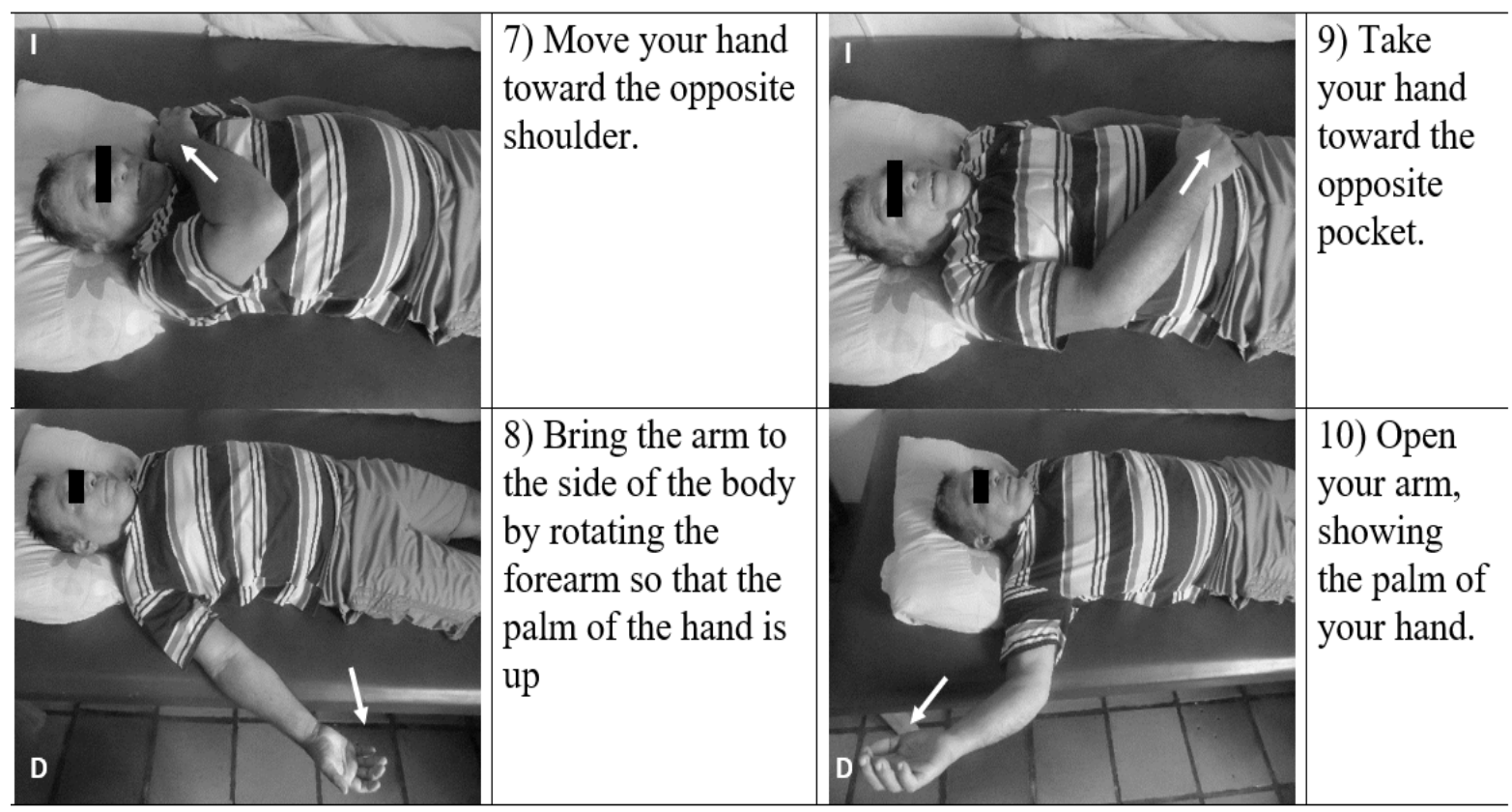

Difficulty: E - Easy; I - Intermediate; D - Difficult 
Figure 3. Moving from Lying Down to Sitting.

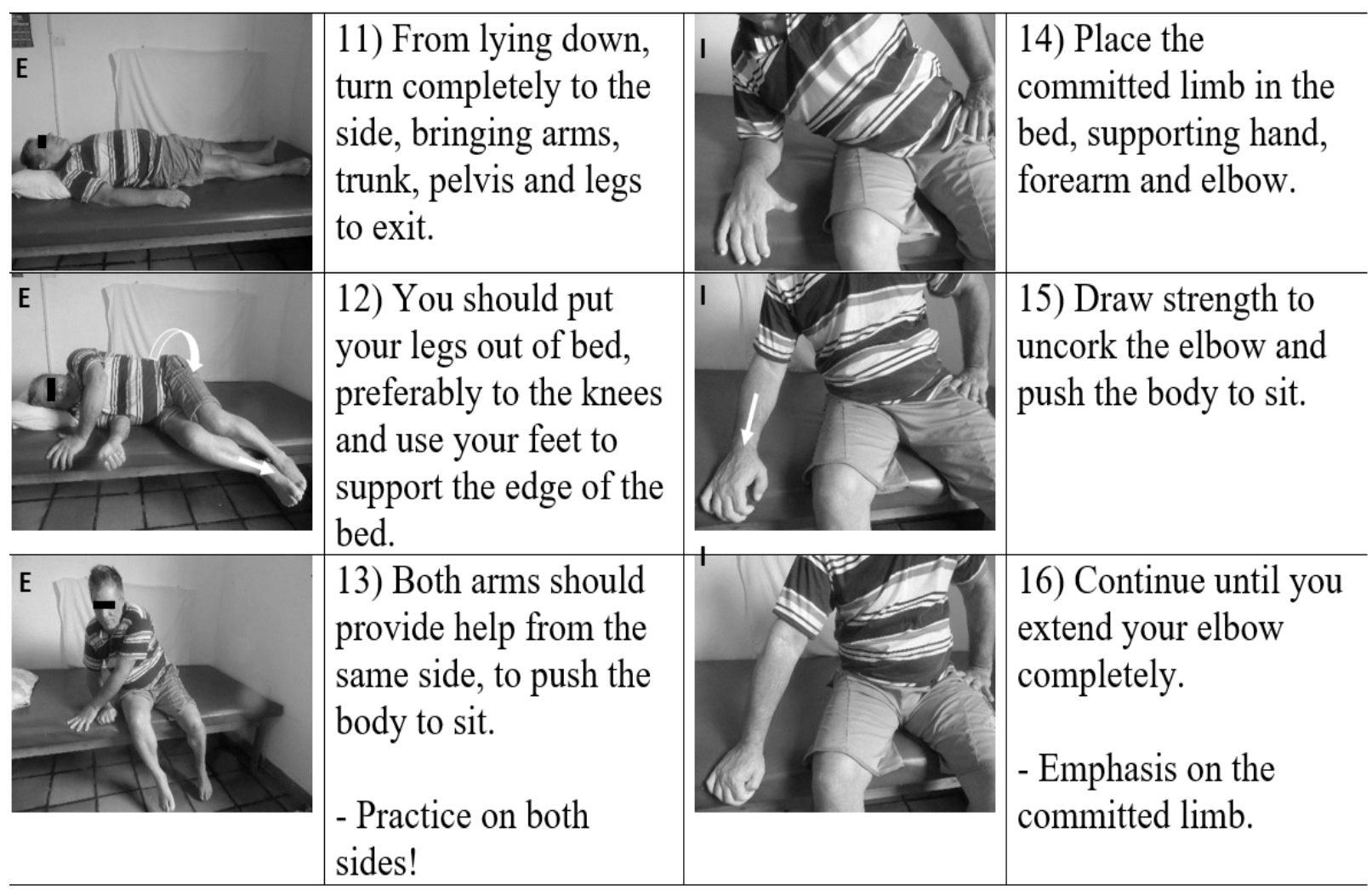

Difficulty: E - Easy; I - Intermediate; D - Difficult

Figure 4. Weight Bearing, Flexibility, and Movement Control Exercises for the Affected Lower Limb
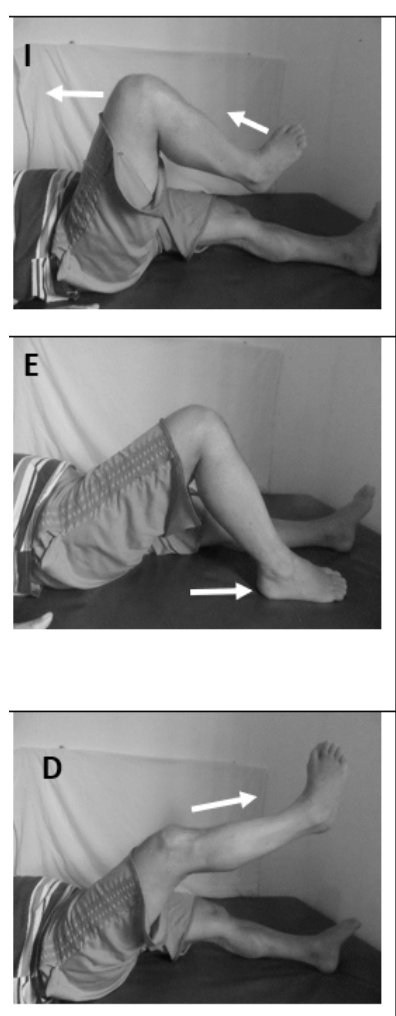

17) Bring the knee toward the chest and try to bring the toe in the same direction.

18) Return the movement by sliding the heel along the bed.

19) When the control of the leg is better, return the movement, that is, stretch the knee in the air, without contact with bed.
20) Cross your compromised leg over your healthy leg. Return it to rest position next to the normal leg.

21) Bend both knees and remain with the soles of the feet in contact with the bed. From this position, turn your legs to your left side.

22) Turn to the right side so as to "twist" your torso.

Difficulty: E - Easy; I - Intermediate; D - Difficult 
Figure 5. Weight Bearing, Flexibility, and Movement Control Exercises for the Affected Lower Limb

\begin{tabular}{|l|l|}
\hline $\begin{array}{l}\text { 23) With both feet } \\
\text { resting on the bed, } \\
\text { raise your pelvis } \\
\text { toward the ceiling. }\end{array}$ & $\begin{array}{l}\text { 26) Lie on your side, } \\
\text { bring your heel } \\
\text { back, just bending } \\
\text { your knee. }\end{array}$ \\
\hline $\begin{array}{l}\text { 24) Repeat the same } \\
\text { position and do not let } \\
\text { the elastic band close } \\
\text { your legs. }\end{array}$ & $\begin{array}{l}\text { 27) Bring your knee } \\
\text { forward and if } \\
\text { possible, do not } \\
\text { touch your foot on } \\
\text { the bed. }\end{array}$ \\
\hline $\begin{array}{l}\text { 25) When there is } \\
\text { better control, keeping } \\
\text { the pelvis in the air, } \\
\text { affected limb } \\
\text { supported, straighten } \\
\text { the opposite leg. }\end{array}$ & $\begin{array}{l}\text { 28) Support both } \\
\text { arms on the wall and } \\
\text { bring the torso } \\
\text { forward to lengthen } \\
\text { the musculature of } \\
\text { the legs. } \\
\text { (keep your knees }\end{array}$ \\
\hline
\end{tabular}

Difficulty: E - Easy; I - Intermediate; D - Difficult

Figure 6. Passing from Sitting to Standing, Exercise for Trunk Mobility and Weight Bearing in the Affected Member

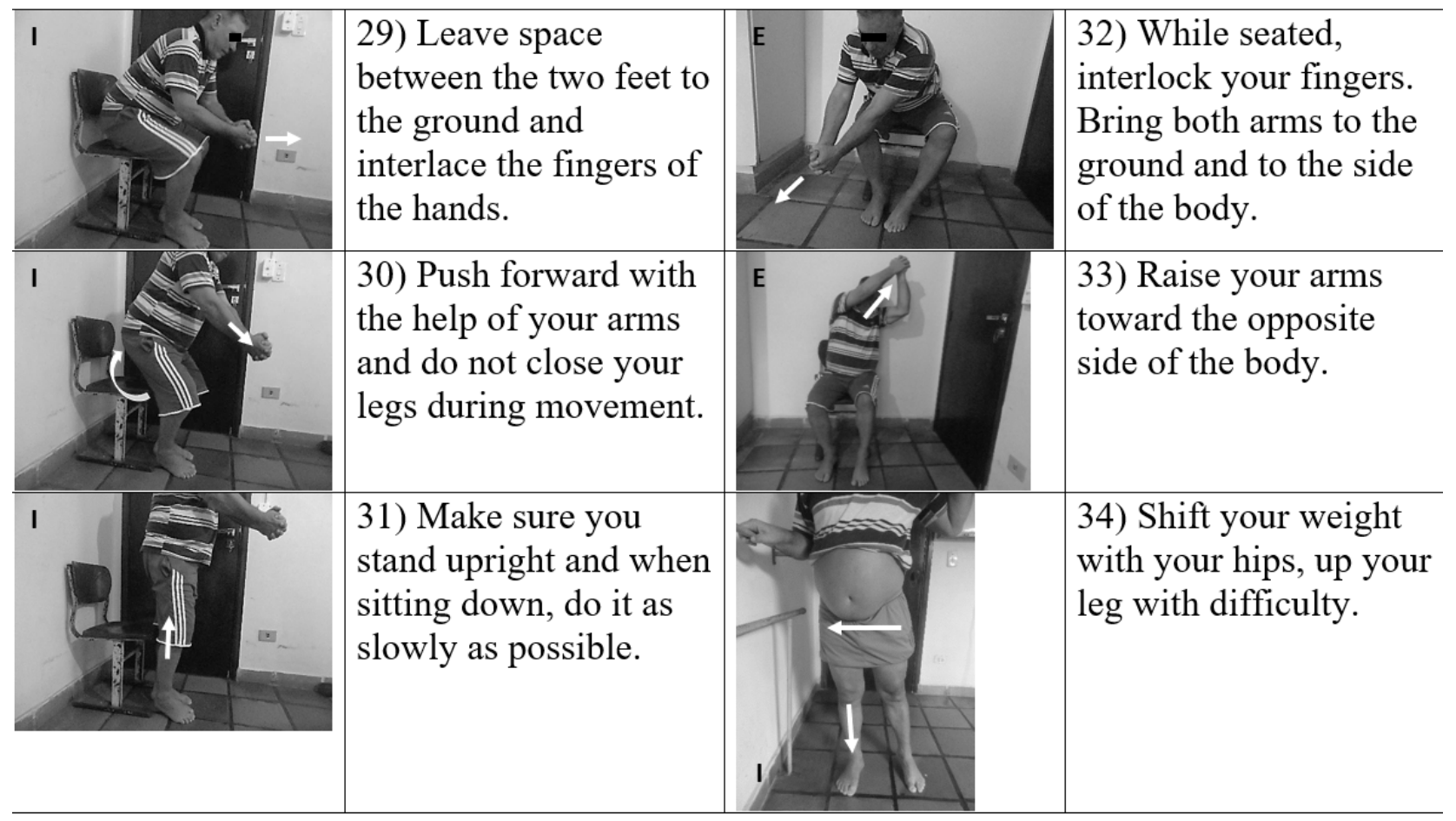

Difficulty: E - Easy; I - Intermediate; D - Difficult 
Figure 7. Weight Bearing and Movement Control Exercises for the Affected Lower Limb.
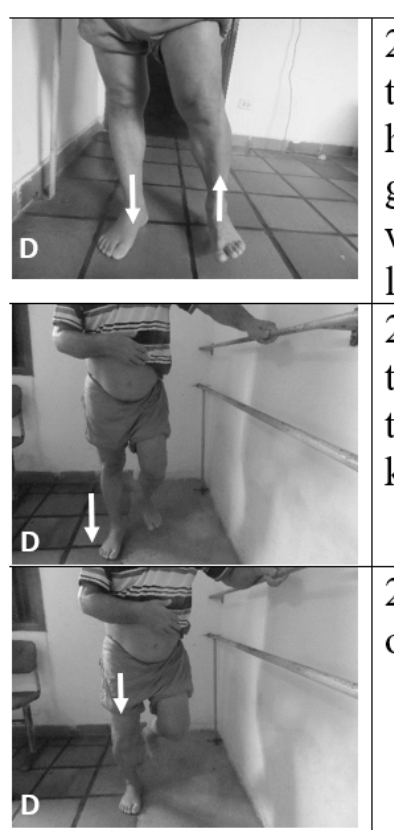

Difficulty: E - Easy; I - Intermediate; D - Difficult

In the first service session, it is considered important to present this tool, selecting the exercises and demonstrating how to use the manual. On subsequent visits, the patient and family member (caregiver) should bring the same, address possible doubts and perform what was requested to verify the correct performance. Even at the time of discharge from physical therapy, it can be determined which activities to follow in order to maintain gains, prevent shortening, deformities and functional weakness $[1,3,5]$.

\section{References}

1. Lang CE, Lohse KR, Birkenmeier RL (2015) Dose and timing in neurorehabilitation: Prescribing motor therapy after stroke. Curr Opin Neurol 28: 549-555.

2. Volz LJ, Rehme AK, Michely J, Nettekoven C, Eickhoff SB, et al. (2016) Shaping Early Reorganization of Neural Networks Promotes Motor Function after Stroke. Cerebral Cortex 26: 2882-2894.

3. Tse T, Binte Yusoff SZ, Churilov L, Ma H, Davis S, et al. (2017) Increased work and social engagement is associated with increased stroke specific quality of life in stroke survivors at 3 months and 12 months post-stroke: a longitudinal study of an Australian stroke cohort. Top Stroke Rehabil 24: 405-414.

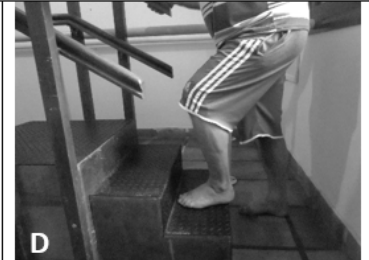

28) Alternate place one of the legs on the step and remove it. Without hitting the way or dragging the step on the turn. 29) It should be done with both legs and as soon as possible without arm support.

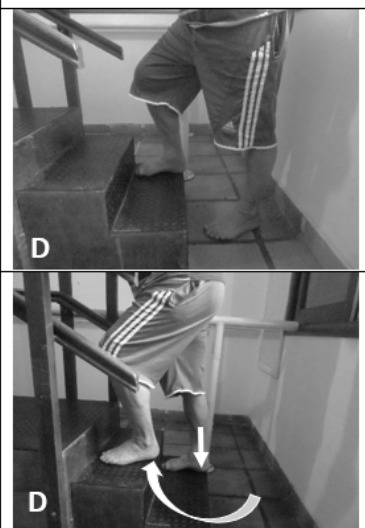

30) Leave the compromised leg on the 1st step, take the other leg on the step above and then return the healthy pen to the ground.
4. Arba F, Quinn T, Hankey GJ, Inzitari D (2017) Determinants of post-stroke cognitive impairment: analysis from VISTA. Acta Neurol Scand 135: 603-607. [Crossref]

5. Powers WJ (2018) Guidelines for the Early Management of Patients With Acute Ischemic Stroke: A Guideline for Healthcare Professionals From the American Heart Association/American Stroke Association. Stroke 49: e46-e110.

6. Lomaglio M, Perry L (2016) A Clinical Guide to Exercise Prescription After Stroke. APTA -American Physical Therapy Association.

7. Billinger AS (2014) Physical activity and exercise recommendations for stroke survivors: a statement for healthcare professionals from the American Heart Association/American Stroke Association. Stroke 45: 2532-2553.

8. A Stroke Recovery Guide - HOPE (2010) National Stroke Association.

9. Winstein CJ, Stein J, Arena R, Bates B, Cherney LR, et al. (2016) On behalf of the American Heart Association Stroke Council, Council on Cardiovascular and Stroke Nursing, Council on Clinical Cardiology, and Council on Quality of Care and Outcomes Research. Guidelines for adult stroke rehabilitation and recovery: a guideline for healthcare professionals from the American Heart Association/American Stroke Association. Stroke 47.

Copyright: $\odot 2018$ Artioli DP. This is an open-access article distributed under the terms of the Creative Commons Attribution License, which permits unrestricted use, distribution, and reproduction in any medium, provided the original author and source are credited. 